Revista Destaques Acadêmicos, Lajeado, v. 9, n. 2, 2017. ISSN 2176-3070

DOI: http://dx.doi.org/10.22410/issn.2176-3070.v9i2a2017.1032

www.univates.br/revistas

\title{
ASSESSORIA DE IMPRENSA POLÍTICA E O AGENDAMENTO
}

\author{
Ederson da Rocha ${ }^{1}$, Carmen Severo ${ }^{2}$
}

Resumo: Identificar o que determina o agendamento das redações de jornais por assessorias de imprensa e como a mídia define os assuntos debatidos pela sociedade são os paradigmas que desafiam este artigo. Para isso, o presente trabalho aplica metodologicamente, uma pesquisa bibliográfica que reúne teorias que formam conceitos e atentam a explicar os paradigmas dessa relação social e comunicativa entre o profissional da assessoria de imprensa e os jornalistas das redações. Esse conjunto de teorias e técnicas de gestão midiática apresentam informações que poderão contribuir com as ações das assessorias de imprensa na intensa e disputada luta por espaço na mídia aos seus assessorados.

Palavras-chave: Assessoria de imprensa. Comunicação. Política. Agendamento.

\section{INTRODUÇÃO}

Nesse mundo democrático, midiático e competitivo da modernidade constante, a criatividade é forte aliada dos profissionais de assessoria de imprensa política, na conquista de espaços nos jornais para divulgação das notícias dos órgãos assessorados. Os releases e informações produzidos pelos assessores de imprensa auxiliam os jornalistas e repórteres de redação. Os pequenos jornais, principalmente, com suas equipes reduzidas e tempo escasso para acompanhamento geral das notícias cotidianas, servem-se regularmente dos materiais enviados pelas assessorias para fechar suas edições.

1 Bacharel em Comunicação Social - Habilitação: Jornalismo pela Univates (2012). Pósgraduando em Docência do Ensino Superior pela UNIASSELVI/IERGS. E-mail: ederocha42@gmail.com

2 Graduação em Pedagogia pela Faculdade de Filosofia Ciências e Letras Imaculada Conceição (1975). Especialização em Administração e Supervisão Escolar pela Universidade Federal de Santa Maria (1993). Especialização em Arte e Educação pela Faculdade de Música Palestrina (1985). Mestrado em Educação pela Universidade Federal de Santa Maria (1999). E-mail: carmen_severo@hotmail.com 
"Para ser é necessário aparecer" (ARENDT, 1993, p. 149). A concretização desta teoria acontece através de pessoas e mecanismos capazes de torná-la realidade. É neste contexto que inserimos o papel da assessoria de comunicação e, especificamente, a assessoria de imprensa. Este setor é fundamental no processo de relacionamento entre a organização assessorada e a mídia. Por isso, teorizar e entender este paradigma é um desafio inevitável para o profissional da comunicação.

Atualmente, ser um ator no âmbito da assessoria de comunicação exige profissionalismo, dedicação e criatividade. As ações propostas para atingir sucesso nesta profissão envolvem diversas áreas do conhecimento e amplo domínio das tecnologias da informação. A comunicação pública envolve planejamento estratégico, rapidez de raciocínio, talento e preparo para lidar com imprevistos e situações adversas. Neste caso, ter capacidade de enfrentar o "mau tempo" deve ser uma das virtudes do assessor de imprensa.

\section{ASSESSORIA DE IMPRENSA NA HISTÓRIA}

A profissão de assessor de imprensa surgiu na passagem dos séculos XIX para XX. Os pioneiros foram os sindicalistas, que difundiam seus ideais. Estes eram revidados pelos empregadores, através dos "house organs" ou publicações da casa. A profissionalização partiu do chinês Ivy Lee que publicava informações empresariais com objetivo de formar a opinião pública. Logo depois os americanos apresentaram e difundiram este serviço na esfera governamental e privada, durante a formatação das sociedades industriais contemporâneas, conforme Mafei (2009).

Todavia, Lorenzon e Mawakdiye (2006) apontam a existência deste serviço ainda nos impérios da Antiguidade, como China, Roma e Pérsia, que destinavam servos de confiança para divulgarem as decisões do Reino. A Espanha de Felipe II e a França de Maria Antonieta e Luiz XVI, no Século XVIII, também se utilizavam deste serviço para levar as informações imperiais ao povo. Os modernos assessores representam a sobrevivência deste antigo portavoz das Idades Antiga e Média.

No Brasil, o governo do ex-presidente Getúlio Vargas (1930-1945) foi pioneiro neste serviço, criando o Departamento de Imprensa e Propaganda (DIP). Este órgão era responsável pelo controle e distribuição de informações da Presidência da República.

\section{ASSESSORIA DE IMPRENSA NA PRÁTICA}

O jornalismo possui diversas facetas no campo da comunicação. Para Marcondes Filho (2000), é uma forma de "publicidade disfarçada". Na política, são as assessorias de imprensa as responsáveis por esta estratégia comunicativa midiática. Conforme Mafei (2009), o trabalho desse profissional baseia-se na produção de informações e envio das notícias da representação política 
aos veículos de comunicação. Portanto, gerencia o relacionamento entre assessorado e imprensa. No caso de uma assessoria política, é o elo de ligação entre a gestão púbica e os cidadãos, por meio da mídia, exercendo o papel de dar transparência às ações governamentais.

A influência dos meios de comunicação na vida política da sociedade é notória, nos mais diversos momentos da história da humanidade. Rüdiger (1998) observa que a ação da comunicação pode ocorrer nas pessoas através de conceitos continuamente internalizados, que geram atitudes e influenciam a sociedade. Desta forma, não somente a mídia influencia o homem e seu comportamento, como o homem a influencia.

Rüdiger (1998) assinala que a mídia alcançou um lugar dominante na vida das pessoas, principalmente após o desenvolvimento do Capitalismo e o que foi constatado nas teorias da Escola de Frankfurt. Os veículos de comunicação passaram a criar as demandas e orientar os costumes e hábitos da civilização, ou seja, agendar os assuntos discutidos na sociedade.

Para Hohlfeldt (2001) mais do que divulgar um produto ou lançálo no mercado, a imprensa acabou desempenhando o papel de criar hábitos, modos de viver e de pensar. Ela define estilos, fabrica modelos identificatórios, testemunhando, assim, o poder das palavras e das imagens sobre os seres humanos. Diante disso, vê-se que a comunicação possui papel fundamental para construção do circuito produtivo do mundo globalizado.

Segundo Mafei (2009), a atividade de assessoria de imprensa conquista cada vez mais seu espaço no mercado da comunicação. As teorias apresentadas nos motivam a concordar que "a assessoria de imprensa é um setor especializado que busca permanentemente o aprimoramento dos fluxos de comunicação no interior das organizações" (LOPES, 2003, p. 9). No ofício da assessoria de imprensa está a função de facilitar o caminho das informações das fontes para os jornalistas, contribuindo fundamentalmente para o sucesso da organização assessorada.

A atribuição básica do assessor de imprensa é administrar as informações jornalísticas das fontes para os meios de comunicação e vice-versa. Outras atividades, observa Lopes (2003), complementam a função como sugestão de pautas por meio da produção de releases; edição de jornais, revistas e vídeos sobre a atuação do assessorado; preparo de textos de apoio, súmulas e sinopses; organização de entrevistas coletivas e individuais; participação direta na elaboração de estratégias da administração.

Pode-se acrescentar, diante do advento da internet, a introdução de outras obrigações, como a atualização de sites, blogs, twitter, facebook e outras plataformas de divulgação dos trabalhos do assessorado. 


\section{CONTRIBUIÇÃO DAS TEORIAS}

Os colunistas de jornais e atualmente, os jornalistas "blogueiros" são os grandes formadores de opinião e devem ser atendidos de forma exclusiva e com profissionalismo. Lopes (2003) ressalta que alguns jornalistas/colunistas se consideram "ombudsman" da sociedade, ou seja, representante do povo ou advogados do leitor. Função incorporada, segundo ele, pela primeira vez pelo Louisville Courier Journal, nos Estados Unidos, em 1967.

Conforme Traquina (2005) e de acordo com os princípios da teoria democrática, vivemos numa "sociedade interpretativa" e o jornalismo é um "mercado de ideias", em que as diversas opiniões da sociedade podem ser ouvidas e interpretadas. É importante destacar que conquistar o "guardião da democracia", como o jornalista é chamado pelo autor, é o papel dos assessores de imprensa.

Corrado (1994) destaca a criação de projetos e ações que despertem a atenção dos jornalistas. Essas ações são construídas a partir da visão estratégica do assessor de imprensa. Duarte (2009) contribuiu dizendo que o plano de comunicação é parte fundamental do planejamento estratégico da comunicação de uma organização. Dessa forma entende-se que os agentes públicos podem ter excelentes ideias e projetos que, se divulgados de forma inadequada, causam efeito negativo perante a sociedade, prejudicando a imagem da marca assessorada.

A execução de um plano de comunicação é que vai levar as informações ao público da forma correta, atingindo os resultados positivos projetados. Portanto, é possível verificar que é preciso estar preparado para administrar a situação em lados opostos. De um lado, orientar o assessorado a "abrir o jogo" nos casos de crise. De outro, administrar a situação para que não sejam publicados excessos por jornalistas que costumam "forçar a barra", na hora de uma matéria polêmica. "Jornalista trabalha com a matéria prima, que é a vida, e as ferramentas, que são as palavras" (MARTINS, 2005, p. 113). Esta afirmação resume a importância dessa atividade no contexto da comunicação política.

Antes de conceituar o agendamento, Rüdiger (2002) nos remete brevemente ao final do século XIX e início do século XX e observa alguns estudos relacionados à época. Grandes estudiosos da época entenderam que deveriam estudar a comunicação perante a sociedade, analisando o efeito estímuloresposta causado pela transmissão da informação de forma homogênea. Com isso os detentores do poder da comunicação poderiam manipular as pessoas através do mecanismo comunicacional, conhecido como teoria hipodérmica, instituída na Escola de Columbia (1940-1960), nos Estados Unidos, importante instituição para o estudo dos meios de comunicação de massa.

Estes estudos foram antecedidos pelo manifesto de fundação dos estudos de comunicação midiática de Lazarsfeld, que baseou a aplicação de métodos capazes de controlar e dirigir as massas. Porém a concepção da teoria 
hipodérmica haveria de vir por terra após a campanha eleitoral de Roosvelt, nos Estados Unidos, em 1940, que sofreu forte combate da mídia americana.

Rüdiger (2002) aponta também os estudos linguísticos de Ferdinand de Saussure, ressaltados no âmbito da semiologia por Roland Barthes e Umberto Eco, como fundamentos que criaram um pensamento crítico em relação ao poder da mídia, estudando o efeito da mensagem sobre o receptor. Mas Elisabeth Noelle-Neumann, nos anos 1970, voltou a constatar a força da comunicação midiática, consolidando o poder de agenda dos media sobre a sociedade. Esta teoria ficou conhecida como espiral do silêncio.

Com base nesse estudo, o fundamentalismo que analisava anteriormente o que a mídia fazia com as pessoas. Posteriormente, passou-se a observar o que as pessoas faziam com a mídia, criando-se a teoria dos usos e gratificações. Dessa forma, interpreta-se que a mídia passa a oferecer sonhos, desejos e aspirações ao público, passando, este a comprar os produtos oferecidos.

Deduz-se que a mídia poderia determinar sobre quais assuntos a sociedade deveria pensar, porém não determinava o que deveria pensar sobre estes assuntos. Isso também pode ser observado por McCombs e Shaw (apud Wolf 1999). Entendia-se que um assunto repetido inúmeras vezes poderia se tornar verdade incontestável e, indiretamente, influenciar o pensamento das pessoas. Na década de 1940 surgem os ensinamentos da Escola de Frankfurt, que determinam o conceito de indústria cultural. Essa teoria volta forte depois dos anos de 1970 quando surgem as indústrias culturais criadoras dos produtos para serem consumidos pela população, que exercem forte influência na manutenção e crescimento financeiro dos veículos midiáticos. A comunicação passa a ser vista sob a perspectiva de uma economia política.

Estes conceitos passaram a nortear teoricamente as técnicas adotadas pelos profissionais da área. A problemática dos efeitos da comunicação de massa e a ascensão da semiótica foram analisadas empiricamente criandose métodos e dados objetivos, mensurando-se as reações das pessoas às mensagens a elas enviadas. Diante desse embasamento explicativo é possível traçar uma definição teórica a respeito do termo agendamento ou agenda-setting da sociedade pelas mídias noticiosas. O termo agenda-setting, para McCombs (2009), quer dizer "fixação de agenda". Este autor talvez seja o mais clássico teórico da hipótese do agendamento da sociedade pela mídia de massa.

Partindo deste princípio, será possível realizar uma conjugação de conceitos que fornecem embasamento teórico para entender como funciona o agendamento das mídias pelas assessorias de imprensa. Pena (2005) afirma que o agenda-setting surgiu nos Estados Unidos. O conceito foi formulado por Maxwell McCombs e Daniel Shaw, em 1972, no artigo da Public Opinion Quarterly, um estudo realizado durante a campanha presidencial de 1968, em Chapel Hill, na Carolina do Norte. 
McCombs e Shaw (apud Traquina, 2002) definem que a agenda-setting é a hipótese segundo a qual a agenda temática dos meios de comunicação impõe os temas de discussão social. Sendo assim, as pessoas, nas suas comunicações interpessoais, discutem prioritariamente sobre os temas abordados pela mídia. Estes assuntos tornam-se agenda púbica. Rogers, Dearing e Bregman (apud Traquina 2002), explicam a teoria do agendamento por meio de estudos empíricos da relação entre agenda midiática e da agenda pública, que define a agenda-setting. $\mathrm{O}$ termo agenda se define como uma lista de questões e acontecimentos que são vistos num determinado ponto do tempo, sendo classificados segundo uma hierarquia de importância.

A intensa variabilidade dos ambientes geográficos e culturais, nos quais o agendamento da mídia ocorre, provoca efeitos completamente distintos. $\mathrm{Na}$ perspectiva de McCombs (2009, p. 65), "o agendamento é um efeito robusto e amplo de comunicação de massa, um efeito que resulta de conteúdo específico nos mass media".

Rüdiger (2002) explica a agenda-setting, argumentando que para agendar a sociedade é preciso agendar a mídia. $\mathrm{O}$ autor aborda a ideia do fluxo de comunicação, seguindo a premissa da hierarquia de conteúdos em pauta, conforme os critérios de noticiabilidade e importância dos fatos. Isso remete à concepção de que a mídia é composta pelas pessoas bem informadas, conhecidas como líderes de opinião, ou seja, os jornalistas e comunicadores. Consequentemente, se reconhece que esses elementos são os responsáveis por difundir a informação para o restante da população, por meio da transmissão de suas interpretações, determinando assim, o que a população deve pensar sobre os assuntos.

A percepção que o público tem de grande parte dos assuntos é fornecida por meio do agendamento proposto pela mídia. Wolf (1999) afirma que a partir deste processo, o destinatário torna-se incapaz de controlar a precisão da representação da realidade social. Com isso, passa a ser dependente das informações fornecidas pelos meios de comunicação para construir sua opinião e apropriar-se da verdade recebida e estabelecida, a respeito dos acontecimentos.

Sublinhando essa crescente dependência cognitiva dos mass media, a hipótese do agenda-setting toma como postulado um impacto direto - mesmo que não imediato - sobre os destinatários, que se configura segundo dois níveis, conforme Wolf (1999). Isso propõe as seguintes percepções: a) a "ordem do dia" dos temas, assuntos e problemas presentes na agenda dos mass media; $b$ ) a hierarquia de importância e de prioridade segundo a qual esses elementos estão dispostos na "ordem do dia".

Por conseguinte, pode-se visualizar que a "ordem do dia" da imprensa é que define os assuntos da pauta de discussões da sociedade, que irão determinar a opinião pública. O processo é coletivo com certo grau de reciprocidade, dividido por Wolf (1999) em fases: 
a) as mídias dão relevo ao acontecimento, apresentando alguns tipos de temas em primeiro plano, na estratégia conhecida como a fase de focalização; midiático;

b) depois vem o framing ou a imposição deste tema no enquadramento

c) em seguida, vem a ligação deste acontecimento a um objeto, que pode ser político, estabelecendo um panorama social reconhecido;

d) finalmente o tema ganha peso e recebe seus "porta-vozes" que irão disseminar a informação, num processo de "empolamento" e envolvimento social. agenda:

McLeod, Becker e Byrnes (apud Wolf 1999, p. 173), definem três tipos de

a) A agenda interpessoal (ou realce individual), que corresponde àquilo que o indivíduo considera serem os temas mais importantes: trata-se de importância pessoal, atribuída a uma questão pela própria pessoa, de acordo com o seu sistema de prioridades; b) A agenda interpessoal (realce comunitário), ou seja, os temas sobre os quais o indivíduo fala ou discute com outros; designa, por isso, uma importância intersubjetiva, isto é, a quantidade de importância efetiva atribuída a um tema, dentro de uma rede de relações e de comunicação interpessoais; c) O terceiro tipo de agenda diz respeito à percepção que um sujeito tem do estado da opinião pública (perceived community salience) (De George, 1981): trata-se do realce captado, ou seja, da importância que o indivíduo pensa que os outros atribuem ao tema; correspondente a um clima de opinião" e pode inserir-se nas chamadas tematizações.

Baseado nos autores, é possível eleger o primeiro tipo de agenda como o mais próximo da existência de um efeito causal direto, sendo mais facilmente observável com as metodologias normalmente utilizadas.

É sabido que os temas disputam entre si os espaços na agenda pública e alguns se sobressaem, tomando maior espaço na arena de discussões sociais. McCombs (2009) afirma que nenhuma sociedade é capaz de discutir vários temas ao mesmo tempo, por isso que alguns se destacam. A afinidade do indivíduo com o tema define se ele é intrusivo ou não intrusivo. Seguindo essa premissa, a importância atribuída pelo público, a estes conteúdos, pode ser influenciada pela mídia, segundo Shaw apud Wolf (1999).

Assim sendo, a influência da mídia nas conversas dos cidadãos advém da confluência entre a agenda midiática e agenda pública. Ao excluírem, incluírem e hierarquizarem os acontecimentos diários, os jornalistas orientam a atenção do público para os assuntos destacados.

Os autores orientam a seguinte conclusão de divisão do processo de agendamento: agenda midiática, consiste nos conteúdos das mídias; agenda 
pública, conceitua a relativa importância dos diversos acontecimentos e assuntos por parte de membros do público; agenda das políticas governamentais, que é o estudo da agenda das entidades governamentais.

Conforme Traquina (2002), os estudos do agendamento são baseados na produção jornalística da informação. Perante a organização do trabalho jornalístico, o processo de agendamento das mídias envolve três categorias de pessoas:

a) news promotors ou promotores de notícias, que identificam uma ocorrência especial e propõem a agenda política governamental, talvez a mais importante das agendas políticas. Estes membros do campo político são agentes especializados que possuem suas próprias agendas políticas;

b) news assemblers, que são os profissionais que transformam um perceptível conjunto finito de ocorrências em acontecimentos públicos, determinando a agenda jornalística e divulgando os fatos;

c) news consumers ou os consumidores de notícias, que assistem às ocorrências disponibilizadas nos meios de comunicação social. Estes últimos membros estão sujeitos à influência das mídias, que ajudam a construir a agenda pública.

Estas informações levam a raciocinar que os assessores de imprensa são os newws promotors da vida pública. Estes profissionais são responsáveis por ter o "faro" de identificar quais fatos são capazes de virar notícias. Rüdiger (2002) acrescenta o envolvimento de trabalhos de pesquisa de opinião pública, sondagens populacionais e ações estratégicas, auxiliadas pela atuação de profissionais especializados em comunicação. São métodos eficazes para traçar o agendamento da sociedade.

Além da teoria do agendamento, este estudo se vale da teoria de gatekeeper, já que trata também das notícias que chegam às redações passíveis de serem selecionadas pelos repórteres e posteriormente encaminhadas à publicação. Conforme Traquina (2005), Kurt Lewin, na década de 1940, foi quem aplicou o termo gatekeeper nos estudos de comunicação de massa. Lewin afirmava que a passagem da notícia por determinados canais depende de um gate (portão), que seria o responsável por deixar esta informação entrar na mídia ou rejeitá-la.

O gatekeeper seria responsável pela autorização das notícias baseadas em regras imparciais ou de um grupo de poder. Nos anos 50 do século XX, a teoria de gatekeeper, é fundamentada por David Manning White, que se baseia no conceito de seleção, minimizando outras dimensões importantes no processo de produção das notícias. Este gatekeeper, segundo Pena (2005), precisa ser convencido que as pautas da assessoria têm relevância e poder de agendar o público consumidor. Indivíduo esse que tem: "o poder de decidir se deixa passar a informação ou se bloqueia", (WOLF, 1999, p. 180). 
Portanto, repara-se que identificar o gatekeeper da redação é tarefa prioritária para o assessor de imprensa. É notável o entendimento que um bom tema, com uma notícia bem construída, de boa procedência poderá influenciar o gatekeeper e a matéria terá chances de ganhar espaço no jornal, dependendo da sua sensibilidade ao tema abordado, a notícia recebe chamada de capa.

\section{ASSESSORIA DE IMPRENSA NA POLÍTICA}

Analisando o cenário jornalístico contemporâneo constata-se que a formação da opinião pública está no topo das prioridades da comunicação quando se trata do ambiente político. Neste caso, o agendamento da mídia, para os políticos, é o fenômeno capaz de manter a imagem pública em evidência.

Duarte (2009) afirma que a maioria dos estudiosos das teorias do agendamento e de gatekeeper entende que as decisões tomadas pelos editores e os jornalistas ao reportar a notícia têm papel importante na construção da realidade política. Sendo assim, o objetivo da maioria dos políticos é interceder na tomada de decisão destes produtores de notícias, transformando certos assuntos de seus interesses em uma epidemia comunicacional para a sociedade. Correia (2010) ratifica essa ideia e diz que os políticos conhecem a influência dos media sobre o eleitorado e investem forte neste mecanismo para conquista de votos.

É fato que os jornalistas não dão conta de cobrir todas as situações e eventos noticiosos do dia a dia. Para isso se valem do auxílio dos departamentos noticiosos das organizações que oferecem quantidades substanciais de informações para atenderem a demanda noticiosa. Os press releases, organizados no estilo de notícias jornalísticas, abastecem as redações com suas sugestões de pauta.

O político necessita de um trabalho capacitado e de eficácia no processo de agendamento dos jornalistas para fazer chegar as mensagens à opinião pública. Então é aí que a atuação da assessoria de imprensa passa a tomar um importante significado, na concepção dos agentes públicos políticos como pode-se observar:

As classificações possíveis das fontes são muito diversas, de acordo com o parâmetro a que se faz referência: por exemplo, podem distinguir-se as fontes institucionais das fontes oficiosas ou as estáveis por oposição às provisórias. Uma caracterização diferente separa as fontes ativas das passivas, segundo o grau de utilização e o tipo de relação que se instituem entre fonte e órgão de informação. Fontes centrais, territoriais e fontes de base são categorias individualizadas não só pela localização espacial, mas também pelo tipo de utilização que delas se faz relativamente ao relevo e à noticiabilidade dos acontecimentos (WOLF, 2009, p. 223) . 
Surge então, a necessidade de identificar, especificadamente, cada fonte, de acordo com sua atuação e importância no cenário comunicativo. $\mathrm{O}$ assessor de imprensa deve se caracterizar como fonte ativa e confiável que atua de forma a se transformar necessária para o trabalho da redação. $O$ fator noticiabilidade é fundamental neste processo. $\mathrm{O}$ objetivo deve ser o de contribuir com o jornalista para a construção do newsmaking, ou seja, oferecer critérios de notícia na sua matéria que apresentem valores suficientes para que seja publicada.

O news promoter precisa fazer parte da rede de fontes dos jornalistas. Isso é possível através da confiabilidade profissional da fonte para a redação. Além de ter bom relacionamento com a imprensa, esta conquista se dá com a elaboração de boas pautas. Os assuntos devem ser atrativos. Segundo Mafei (2009, p. 90), "qualquer assunto pode se transformar em sugestão de pauta, desde que devidamente contextualizado". Ou seja, bons textos, com títulos atrativos e fotos de qualidade, contribuem muito com o agendamento das redações.

Martins (2005) sublinha que o poder da fonte não deve ser confundido com pressões, chantagens, jabás e outros tipos de artimanhas interesseiras do sistema de manipulação existente. Estas estratégias sorrateiras geralmente não passam pelos critérios de noticiabilidade exigidos pelos manuais de redações jornalísticas. Para tanto, verifica-se que o promotor de notícias precisa estar ciente da sua missão e saber que está tratando com os principais fornecedores de agendas que pautam a sociedade, os veículos de comunicação. Seguindo esta linha de raciocínio, deduz-se a comunicação pública, sabendo utilizar a imprensa, está diante do mecanismo mais eficaz para pautar os temas a serem discutidos pela população.

No Brasil, o Congresso Nacional é um cenário especial propício ao agendamento. Os políticos, que se acham cônscios do poder de agendamento dos veículos de mídia, são capazes de criar situações para chamar atenção da imprensa, os chamados "meta-acontecimentos". Vários assessores de imprensa do Congresso destacam que este é seu real papel, pois tentam tornar atrativos, os assuntos que envolvem os seus parlamentares e visam provocar o esperado "eco" a estes fatos.

Os consumidores de notícias elegem os assuntos veiculados na imprensa como os mais importantes. Pena (2005) afirma que, por terem o poder de agendar as conversas a serem debatidas pela comunidade, os meios de comunicação são a principal ligação entre os acontecimentos do mundo e as imagens desses acontecimentos na mente das pessoas. Portanto, este é o caminho estratégico para atingir o alvo principal do assessor de imprensa e, obviamente, do político: o público.

Atuação da comunicação política divulga as notícias e causa efeitos eleitorais. Estes efeitos precisam ser planejados para atingir o êxito esperado. $\mathrm{O}$ segredo está na forma como a informação é colocada ao leitor dos jornais, alvo da recepção. Para que este processo ocorra com sucesso, Mafei (2009) alerta que 
o entrosamento entre o assessor de imprensa e o jornalista da redação deve ser "perfeito".

A imprensa é considerada o "quarto poder", em alusão aos três poderes: Executivo, Legislativo e Judiciário, que administram uma nação. Esta força da mídia é capaz de construir ou, até mesmo, destruir qualquer imagem. Martins (2005) afirma que a política está cada vez mais dependente dos meios de comunicação de massa e capaz de difundir uma interpretação da realidade com qualidade própria.

Mafei (2009) aborda o "jogo de interesses" existente entre as partes. Estas observações formatam a constatação de que de um lado está o político que pretende manter-se no comando das decisões, de outro lado está o jornalista que preza pela informação ao público e, ao mesmo tempo, depende da venda das notícias para crescimento profissional e econômico próprio.

Martins (2005) entende que o uso adequado da mídia deve ser auxiliado por ações de marketing, incluindo matérias jornalísticas sobre temas estratégicos, elaboradas por profissionais capacitados em assessoria de imprensa, capazes de agregar valor à imagem pública. Ele recomenda o uso do marketing não somente em campanhas eleitorais, mas de forma permanente em todas as ações de comunicação do representante político. Por isso, na política, todas as ações devem ser planejadas para atingir as metas almejadas, estabelecendo relação de confiança e credibilidade com o público alvo.

Duarte (2009) sugere que o profissional da assessoria de imprensa entenda, não apenas de jornalismo e relações públicas, mas também de política e esteja inteiramente inserido ao grupo da administração pública com exata noção da ideologia do governo para o qual trabalha. Depreende-se a tese que o assessor de imprensa precisa mostrar ao jornalista, através de releases e outras informações, que conhece política.

É obrigação estar bem informado sobre os trâmites legais que envolvem o sistema. Martins (2005) exemplifica isso, referindo-se aos jornalistas que fazem cobertura ou trabalham nas assessorias de imprensa do Congresso Nacional, em Brasília:

Conheça as regras do jogo. Alguém pode ser um bom repórter esportivo no Brasil se não souber o que é um impedimento ou um tiro livre indireto, ou se não estiver familiarizado com o regulamento do próximo Brasileirão? Claro que não. O mesmo raciocínio vale para a política. O repórter que cobre a área tem de conhecer as regras do jogo. Não é obrigado a ser um especialista em regimento interno da Câmara e do Senado, nem um constitucionalista de mão cheia, mas precisa dominar os fundamentos do funcionamento do congresso e ter uma noção básica da Constituição (MARTINS, 2005, p. 80). 
Deste modo, ter o mínimo de percepção política e conhecer o ambiente que trabalha, é fundamental para o assessor de imprensa.

\section{APRECIAÇÃO FINAL}

As teorias aqui abordadas poderão contribuir epistemologicamente na construção dos planejamentos estratégicos de assessorias de imprensa de órgãos públicos, assim como auxiliar outros estudantes em seus trabalhos

acadêmicos. É preciso levar em conta que a assessoria de imprensa cobre também acontecimentos, portanto é agendada pelos fatos sociais e não é somente criadora de fatos. Sendo assim, o órgão ou indivíduo assessorado deve contribuir neste processo com pautas positivas.

Os autores estudados tratam empiricamente das formas e estratégias de agendamento do público, sobre os assuntos a serem discutidos pela sociedade, utilizando-se do agendamento dos jornalistas. Diante das ideias aqui relatadas conclui-se que, para o assessor de imprensa (new promoter) agendar o jornalista (gatekeeper) que, por sua vez, agenda o consumidor de informação (o público leitor), o produto (a notícia) precisa ter qualidade e credibilidade na informação enviada.

As teorias conjugadas neste estudo afirmam que cabe ao assessor de imprensa oferecer subsídios às redações e contribuir na elaboração das matérias da newsmaking. Através do estudo da influência dos news promoters sobre os gatekeepers foi possível constatar que a boa relação entre as partes, a acessibilidade do assessor, os critérios de noticiabilidade e a elaboração de matérias diferenciadas e atraentes são critérios essenciais no sucesso da profissão de assessoria de imprensa.

\section{REFERÊNCIAS}

ARENDT, Hannah. A Dignidade da Política: filosofia. Santa Maria: Sebo Café, 1993.

CORRADO, Frank M. A Força da Comunicação. São Paulo: Makron Books, 1994.

CORREIA, João Carlos; FERREIRA, Gil Baptista; SANTO, Paula do. Conceitos de Comunicação Política. Livros LabCom, Série: Estudos em Comunicação, Covilhã 2010. Escola Superior de Educação de Coimbra. Disponível em: <http://www. livroslabcom.ubi.pt/pdfs/20110817-correia_conceitos_2010.pdf>. Acesso em: $10 \mathrm{de}$ out. 2014.

DUARTE (org.), Jorge. Assessoria de imprensa e relacionamento com a mídia: teoria e técnica. 2. ed. São Paulo: Atlas, 2009.

HOHLFELDT, Antonio, MARTINO, Luiz C. \& FRANÇA, Vera Veiga. Teorias da Comunicação: conceitos, escolas e tendências - A Escola de Frankfurt. São Paulo: Vozes, 2001. 
KOPPLIN, Elisa, FERRARETTO, Luiz Artur. Assessoria de Imprensa: teoria e prática. 4. ed. Porto Alegre: Sagra Luzzatto, 2001.

LOPES, Boanerges. O que é assessoria de imprensa. São Paulo: Brasiliense, 2003.

LORENZON, Gilberto, MAWAKDIYE, Alberto. Manual de assessoria de imprensa. 2. ed. Campos do Jordão: Mantiqueira, 2006.

MAFEI, Maristela. Assessoria de imprensa: como se relacionar com a mídia. 3. ed., $2^{\mathrm{a}}$ reimpressão. São Paulo: Contexto, 2009.

MARCONDES FILHO, Ciro. Comunicação \& Jornalismo - A Saga dos Cães Perdidos. São Paulo, Hacker Editores, 2000.

MARTINS, Franklin. Jornalismo Político. São Paulo: Contexto, 2005.

MCCOMBS, Maxwell. A Teoria da Agenda. A mídia e a opinião pública. Tradução de Jaques A. Wainberg. Petrópolis: Vozes, 2009.

PENA, Felipe. Teorias do Jornalismo. São Paulo: Contexto, 2005.

RÜDIGER, Francisco. Ciência social crítica e pesquisa em comunicação. São Leopoldo: Ed. Unisinos, 2002.

Introdução à teoria da comunicação. São Paulo: Edicon, 1998.

TRAQUINA, Nelson. O estudo do jornalismo no século XX. São Leopoldo: Ed. Unisinos, 2002.

. Teorias do Jornalismo: por que as notícias são como são. 2. ed. Florianópolis: Ed. Insular, 2005.

WOLF, Mauro. Teorias da Comunicação: Mass Media: Conceitos e Paradigmas, Novas Tendências, Efeitos a longo prazo, Newsmaking. 5. ed. Lisboa: Editora Presença, 1999. 